Research Article

\title{
Effects of Gd211 Particles Characteristic in the Precursor Pellets on the Levitation Force of Single-Domain GdBCO Bulks Prepared by the Gd + 011 TSIG Method
}

\author{
Xiaochun Yuan $\mathbb{D}^{1,2}$ and Wanmin Yang $\mathbb{D}^{1}$ \\ ${ }^{1}$ College of Physics and Information Technology, Shaanxi Normal University, Xi'an 710062, China \\ ${ }^{2}$ College of Science, Xi'an University of Science and Technology, Xi'an 710054, China \\ Correspondence should be addressed to Wanmin Yang; yangwm@snnu.edu.cn
}

Received 27 February 2018; Revised 1 July 2018; Accepted 18 July 2018; Published 26 August 2018

Academic Editor: Simo-Pekka Hannula

Copyright (c) 2018 Xiaochun Yuan and Wanmin Yang. This is an open access article distributed under the Creative Commons Attribution License, which permits unrestricted use, distribution, and reproduction in any medium, provided the original work is properly cited.

In this paper, single-domain GdBCO bulks have been fabricated by a new Gd +011 TSIG method with precursor solid phase pellets (PSPPs) of different Gd211 particle sizes and distributions, prepared by solid state reaction with well-mixed $\left(\mathrm{Gd}_{2} \mathrm{O}_{3}+\mathrm{BaCuO}_{2}\right)$ pellets at different temperatures. The novel results indicated that (1) the average size of Gd211 particles in PSPP is monotonically increasing with increasing the sintering temperature up to $1200^{\circ} \mathrm{C}$. (2) With increasing the sintering temperature from 950 to $1200^{\circ} \mathrm{C}$, the porous ratio and the density of the PSPP are, respectively, monotonically decreasing and increasing. Furthermore when the sintering temperature is less than $1000^{\circ} \mathrm{C}$, the porous ratio is higher and the density is lower than the values of the pressed pellets. (3) With increasing the sintering temperature, the average size of Gd211 particles in the GdBCO bulk first decreases and then increases. In addition, the smallest Gd211 particles are obtained in the sample sintered at $1050^{\circ} \mathrm{C}$. (4) The maximum levitation force is obtained in the sample sintered at $1150^{\circ} \mathrm{C}$ with a relatively larger size of $\mathrm{Gd} 211$ particles and lower porosity. This result is significant when fabricating high-quality GdBCO bulk superconductors by controlling the porosity, Gd211 particle size, and their distribution characteristic.

\section{Introduction}

High-temperature REBCO bulk superconductors (RE is $\mathrm{Yb}$, Y, Gd, Sm, Nd, etc.) are characterized by larger levitation force, higher trapped field, and self-stabilized levitation. These advantages lead to many applications such as magnetic bearing, flywheel, high-field permanent magnets, and levitated transportation systems [1-6]. In order to obtain large single-grain REBCO bulks without weak links, the top seeding technique is employed to avoid the heterogeneous nucleation and promote the growth of the $\mathrm{REBa}_{2} \mathrm{Cu}_{3} \mathrm{O}_{7-\mathrm{y}}$ grain epitaxial grown from the seed to a large scale [7-10]. Top-seeded infiltration growth (TSIG) technique is one of the most popular methods for fabrication of single-grain REBCO bulk superconductors. In the traditional TSIG process, a $\mathrm{RE}_{2} \mathrm{BaCuO}_{5}$ (RE211) solid phase pellet and a liquid phase pellet containing $\mathrm{REBa}_{2} \mathrm{Cu}_{3} \mathrm{O}_{7-\mathrm{y}}$ and $\mathrm{Ba}_{3} \mathrm{Cu}_{5} \mathrm{O}_{8}$ have to be prepared. So, the traditional TSIG process will not only take a long time and expensive cost but is also inefficient during the fabrication of single-domain REBCO superconductor.

In order to reduce the cost and simplify the fabrication process, we have invented a new RE +011 TSIG method to fabricate single-domain REBCO superconductor by using only one precursor powder $\mathrm{BaCuO}_{2}$ (011) [11-15]. The traditional solid phase $\mathrm{RE} 211$ and the traditional liquid phase $\left(\mathrm{REBa}_{2} \mathrm{Cu}_{3} \mathrm{O}_{7-\mathrm{y}}\right.$ and $\left.\mathrm{Ba}_{3} \mathrm{Cu}_{5} \mathrm{O}_{8}\right)$ are, respectively, replaced with the new solid phase $\left(\mathrm{RE}_{2} \mathrm{O}_{3}+\mathrm{xBaCuO}_{2}\right)$ and $\mathrm{Y}_{2} \mathrm{O}_{3}+6 \mathrm{CuO}+10 \mathrm{BaCuO}_{2}$. This method has a considerable number of advantages, for example, improving the production efficiency, reducing the preparation cost, simplifying the experiment process, and enhancing the physical 
properties of REBCO bulk compared with the traditional TSIG ways. However, the size of the Gd211 particle is significantly larger in the single-domain GdBCO samples prepared by the Gd+011 TSIG method [11]. Now, the question arises how to reduce the size of Gd211 particles and improve the physical properties. It is necessary to reveal the relationship between the microstructure of the precursor solid phase pellet (PSPP) and the microstructure of the single-domain GdBCO samples. Furthermore, it is required to determine the relationship among the microstructure of the PSPP, the microstructure of the single-domain GdBCO samples, and the superconducting properties. The latter two steps are essential scientific problems to be solved in order to improve the superconducting properties of single-domain GdBCO samples.

We have prepared a series of PSPP samples with varying density and $\mathrm{Gd} 211$ particle size by sintering the new solid phase $\left(\mathrm{Gd}_{2} \mathrm{O}_{3}+\mathrm{BaCuO}_{2}\right)$ at different temperatures. Based on the prepared samples, a series of single-domain GdBCO bulks has been fabricated by the Gd + 011 TSIG technique. The macroscopic morphology and microstructure of the PSPP and single-domain GdBCO bulks were observed and analyzed. The effects of PSPP on the microstructure and levitation force of single-domain GdBCO bulks have also been investigated based on these samples.

\section{Experimental Procedure}

The precursor powder $\mathrm{BaCuO}_{2}$ (011) was prepared by the conventional solid state reaction method using the raw materials $\mathrm{BaCO}_{3}$ (purity 99.9\%) and $\mathrm{CuO}$ (purity 99.9\%) in air. The powder of $\mathrm{Gd}_{2} \mathrm{O}_{3}$ (purity $99.9 \%$ ) and $\mathrm{BaCuO}_{2}(011$ ) were weighed according to the molar ratio $\mathrm{Gd}_{2} \mathrm{O}_{3}$ : $\mathrm{BaCuO}_{2}=1: 1$ and well mixed by a ball-milling machine. Consequently, pressed into the pellets of diameter $20 \mathrm{~mm}$. The pressed pellets prepared in this way were sintered at different temperatures $(950,1000,1050,1100,1150$, and $1200^{\circ} \mathrm{C}$ ) for $6 \mathrm{~h}$ in the air and furnace cooled to room temperature. The resulting sintered samples were used as the precursor solid-phase pellet (PSPP) for the Gd+011 TSIG process. The liquid phase pellets were prepared from a wellmixed $\mathrm{Y}_{2} \mathrm{O}_{3}, \mathrm{CuO}$, and 011 powder, which were weighed according to the molar ratio $\mathrm{Y}_{2} \mathrm{O}_{3}: \mathrm{CuO}: 011=1: 6: 10$, followed by being pressed into the pellets of $30 \mathrm{~mm}$ in diameter. Furthermore, $\mathrm{Y}_{2} \mathrm{O}_{3}$ or $\mathrm{Yb}_{2} \mathrm{O}_{3}$ was pressed into a plate of thickness $2 \mathrm{~mm}$ and diameter $30 \mathrm{~mm}$ to support the liquid phase at elevated temperature. The configuration of the precursor sample consisted of three cylindrical pellets and stacked up together along their coaxial line: the top one being the PSPP, followed by the liquid phase pellet and the $\mathrm{Y}_{2} \mathrm{O}_{3}$ or $\mathrm{Yb}_{2} \mathrm{O}_{3}$ pellet. Finally, a NdBCO seed was placed on the top surface of the PSPP to promote the epitaxial growth of the GdBCO superconductor during the TSIG process.

The precursor sample was (1) heated up to $920^{\circ} \mathrm{C}$ at a rate of $120^{\circ} \mathrm{C} / \mathrm{h}$, (2) heated up to $1065^{\circ} \mathrm{C}$ at a rate of $60^{\circ} \mathrm{C} / \mathrm{h}$, (3) held for $1 \mathrm{~h}$ to ensure complete infiltration of liquid into the PSPP, (4) cooled to $1040^{\circ} \mathrm{C}$ at a rate of $60^{\circ} \mathrm{C} / \mathrm{h}$; (5) the samples were cooled slowly at a rate of $0.3^{\circ} \mathrm{C} / \mathrm{h}$ to $1015^{\circ} \mathrm{C}$, and (6) the samples were cooled to room temperature at a rate of $120^{\circ} \mathrm{C} / \mathrm{h}$. The resulting grown samples were annealed in flowing oxygen at temperature ranging from 450 to $350^{\circ} \mathrm{C}$ for $200 \mathrm{~h}$ so that the single-grain GdBCO bulks could be of superconducting properties.

Microstructure of the PSPP and the single-domain GdBCO bulks were investigated by a scanning electron microscope (SEM). The levitation forces of the GdBCO bulks were measured at $77 \mathrm{~K}$ under a zero-field cooling state by self-designed magnetic force and magnetic field measurement system [16].

\section{Results and Discussion}

3.1. The Morphology and Density of the PSPP. Figure 1 is the morphology of the PSPP with the same initial new solid phase source of $\left(\mathrm{Gd}_{2} \mathrm{O}_{3}+\mathrm{BaCuO}_{2}\right)$ sintered at different temperatures. As can be seen from Figure 1, the pressed pellet was of gray color and made of well-mixed $\mathrm{Gd}_{2} \mathrm{O}_{3}$ and 011 powders. After sintering at $950^{\circ} \mathrm{C}$, some of the $\mathrm{Gd}_{2} \mathrm{O}_{3}$ reacted with 011 and formed $\mathrm{Gd} 211$ phase, causing the color to turn from gray to yellow-green. When the sintering temperature exceeded $1000^{\circ} \mathrm{C}, \mathrm{Gd}_{2} \mathrm{O}_{3}$ well reacted with 011 and the PSPP changed to Gd211 phase, and the color of the PSPP changed from green to dark green when the sintering temperature increased to $1200^{\circ} \mathrm{C}$.

The density of the PSPP was plotted as a function of sintering temperature as shown in Figure 2. As can be observed from Figure 2, the density of the PSPP increases as sintering temperature increases from 950 to $1200^{\circ} \mathrm{C}$. The density of the PSPP increases from 3.42 to $3.7,4.41,4.82$, 4.93 , and $5.04 \mathrm{~g} / \mathrm{cm}^{3}$, when sintering temperature increases from 950 to $1000,1050,1100,1150$, and $1200^{\circ} \mathrm{C}$. This is agreed with the traditional RE211 solid-phase pellets [17]. The density of the PSPP sintered in the range from 950 to $1000^{\circ} \mathrm{C}$ was in the range from 3.42 to $3.7 \mathrm{~g} / \mathrm{cm}^{3}$, respectively, lower than $3.85 \mathrm{~g} / \mathrm{cm}^{3}$ of the pressed sample. This is much different from the traditional RE211 solid-phase pellets [17], which are closely related with the chemical composition of the new solid phase of $\left(\mathrm{Gd}_{2} \mathrm{O}_{3}+\mathrm{BaCuO}_{2}\right)$ and the microstructure of the samples sintered at different temperatures.

3.2. Microstructure of the PSPP. Figure 3 is the SEM showing the PSPP sintered at different temperatures. As we have mentioned in Section 2, the pressed PSPP (Figure 3(a)) is composed of $\mathrm{Gd}_{2} \mathrm{O}_{3}$ and 011 powder. There are several large dark particles in Figure 3(a) which correspond to the 011 phase. The 011 phase particles are melted and reacted with $\mathrm{Gd}_{2} \mathrm{O}_{3}$ powder to form $\mathrm{Gd} 211$, when the pressed PSPP is sintered at $T_{\mathrm{s}} \geq 950^{\circ} \mathrm{C}$, and thus resulted in the formation of the Gd211 particles and pores in the samples, as shown in Figures 3(b)-3(g). There are many smaller and nanometer Gd211 particles as well as relatively larger pores appeared in the sample, as shown in Figure 3(b). The above process results in a reduction of the density to $3.42 \mathrm{~g} / \mathrm{cm}^{3}$ compared with the pressed PSPP $\left(3.85 \mathrm{~g} / \mathrm{cm}^{3}\right)$. The size of the $\mathrm{Gd} 211$ particles and the pores are increasing and decreasing with increasing the sintering temperature. This causes the density of PSPP gradually to increase from 3.70 to $5.04 \mathrm{~g} / \mathrm{cm}^{3}$, when 


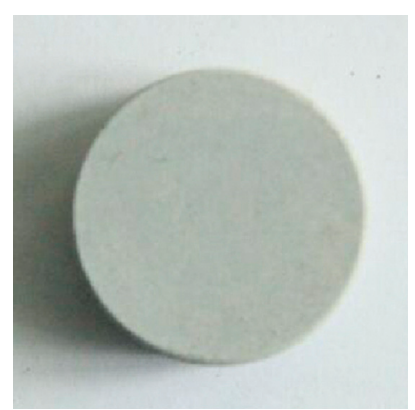

(a)

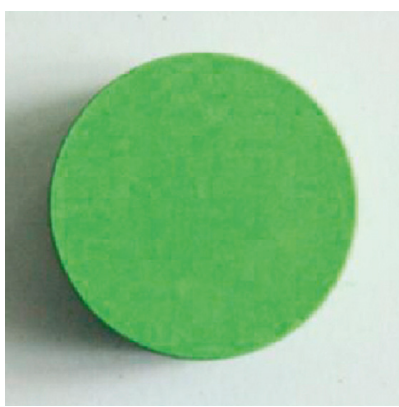

(b)



(c)

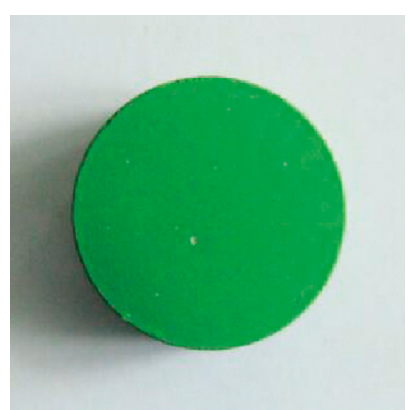

(d)



(e)

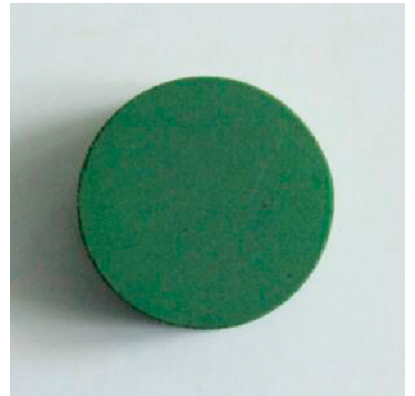

(f)

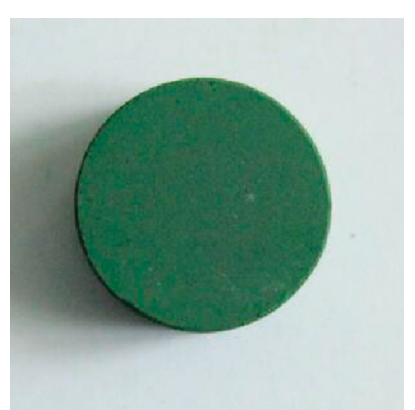

(g)

Figure 1: The morphology of the PSPP with the same initial new solid phase $\left(\mathrm{Gd}_{2} \mathrm{O}_{3}+011\right)$ sintered at different temperatures. (a) $25^{\circ} \mathrm{C}$ (unsintered), (b) sintered at $950^{\circ} \mathrm{C}$, (c) $1000^{\circ} \mathrm{C}$, (d) $1050^{\circ} \mathrm{C}$, (e) $1100^{\circ} \mathrm{C}$, (f) $1150^{\circ} \mathrm{C}$, and (g) $1200^{\circ} \mathrm{C}$.

the sintering temperature increases from 1000 to $1200^{\circ} \mathrm{C}$. The particles have been identified with the energy dispersive spectrometer (EDS) during the microstructure observation by SEM, and the results indicate that $\mathrm{Gd}, \mathrm{Ba}$, and $\mathrm{Cu}$ elements are in the molar ratio $\mathrm{Gd}: \mathrm{Ba}: \mathrm{Cu}=2: 1: 1$, which identified that these are Gd211 particles. The mean size of Gd211 particles for each sample was calculated by an international common software Nano Measurer. As we can see from Figure 3, The average size of the Gd211 particles is either $1.65,2.45,3.33,3.64$, or $4.23 \mu \mathrm{m}$ in the samples sintered at temperature $1000,1050,1100,1150$, or $1200^{\circ} \mathrm{C}$, respectively.

\subsection{Morphology of the Single-Domain GdBCO Bulks.} Figure 4 is the morphology of the single-domain GdBCO samples prepared by the Gd+011 TSIG method with the PSPP of the same initial new solid phase $\left(\mathrm{Gd}_{2} \mathrm{O}_{3}+011\right)$ sintered at different temperatures 25 (corresponding to the unsintered sample), 950, 1000, 1050, $1100,1150^{\circ} \mathrm{C}$, and $1200^{\circ} \mathrm{C}$, denoted as S1, S2, S3, S4, S5, S6, and S7, respectively. As can be seen from Figure 4, all the samples exhibit clear, fourfold growth sectors on their top surface, indicating that they are grown in the form of a single domain [18]. In addition, no spontaneous GdBCO grains were observed in the samples.

\subsection{Levitation Force of the Single-Domain GdBCO Samples.} The levitation forces of the GdBCO samples were measured under a zero-field cooling state at $77 \mathrm{~K}$ by a customized laboratory-made instrument. A magnet with a diameter $20 \mathrm{~mm}$ and a surface field of $0.5 \mathrm{~T}$ was employed for the

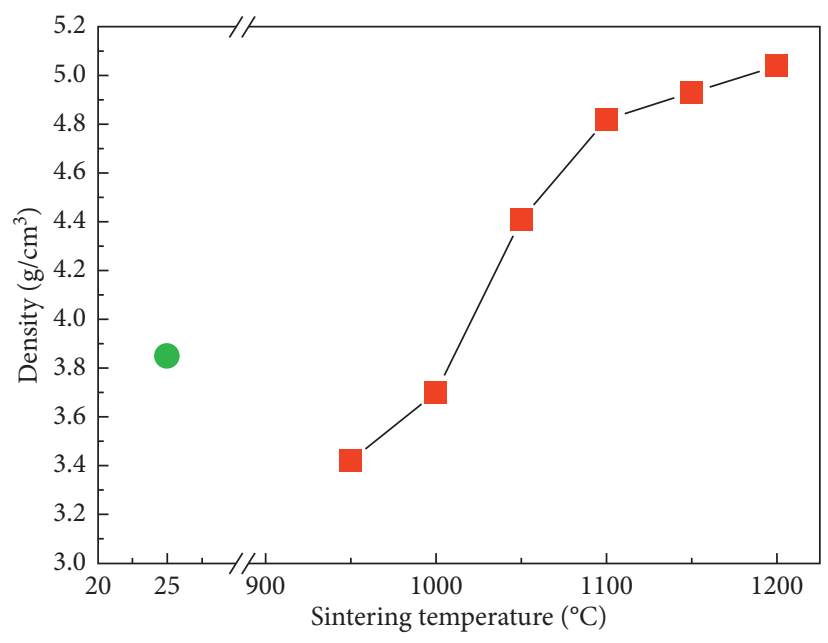

FIGURe 2: The density of the PSPP with the same initial new solid phase $\left(\mathrm{Gd}_{2} \mathrm{O}_{3}+011\right)$ sintered at different temperatures.

levitation force measurements. The maximum levitation force was achieved at the smallest gap $(0.5 \mathrm{~mm})$ between the magnet and the GdBCO samples. The levitation force versus distance (between the magnet and the samples) curves are shown in Figure 5. The insert in Figure 5 shows the dependence of the maximum levitation force $(N)$ on the sintering temperature of the PSPP varying from 25 to $1200^{\circ} \mathrm{C}$. As can be seen from the figure, the maximum levitation force monotonically increases from 25.1 to $38.1 \mathrm{~N}$ with the increasing sintering temperature from 25 (corresponding to the unsintered sample) to $1150^{\circ} \mathrm{C}$. Furthermore, 


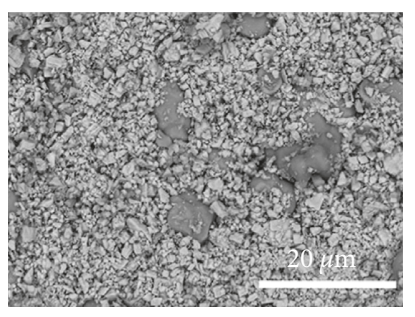

(a)

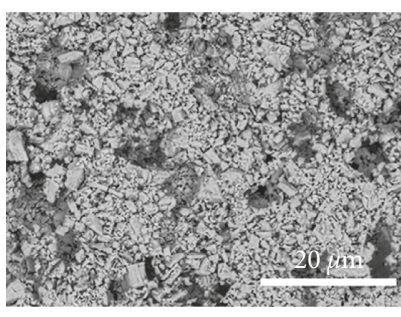

(b)

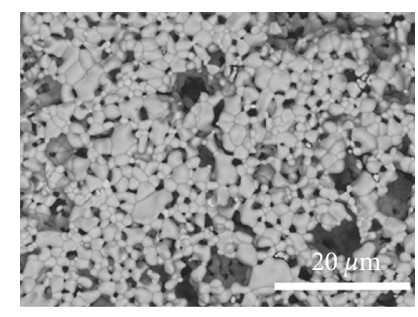

(c)



(d)

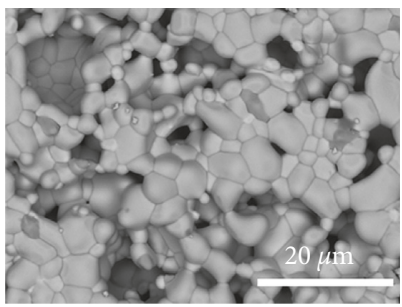

(e)

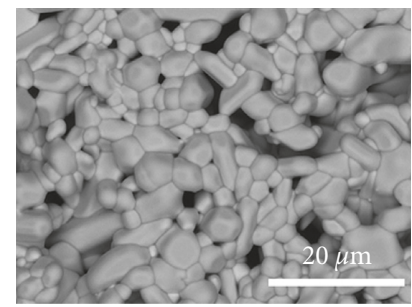

(f)

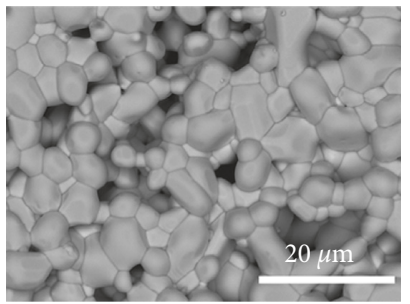

(g)

Figure 3: The SEM pictures of the PSPP with the same initial new solid phase $\left(\mathrm{Gd}_{2} \mathrm{O}_{3}+011\right)$ sintered at different temperatures (a) $25^{\circ} \mathrm{C}$ (unsintered), (b) sintered at $950^{\circ} \mathrm{C}$, (c) $1000^{\circ} \mathrm{C}$, (d) $1050^{\circ} \mathrm{C}$, (e) $1100^{\circ} \mathrm{C}$, (f) $1150^{\circ} \mathrm{C}$, and (g) $1200^{\circ} \mathrm{C}$.

it can be observed that the maximum levitation force decreases in the range $1150^{\circ} \mathrm{C}-1200^{\circ} \mathrm{C}$.

3.5. Microstructure of the Single-Domain GdBCO Samples. Figure 6 is the SEM photographs of the GdBCO samples. It can be seen from Figures $6(\mathrm{a})-6(\mathrm{~g})$ that there are many gray particles distributed in the $\mathrm{GdBa}_{2} \mathrm{Cu}_{3} \mathrm{O}_{7-\mathrm{y}}(\mathrm{Gd} 123)$ phase matrix. The gray particles have been identified with EDS, and the results indicate that $\mathrm{Gd}, \mathrm{Ba}$, and $\mathrm{Cu}$ elements are in the molar ratio $\mathrm{Gd}: \mathrm{Ba}: \mathrm{Cu}=2: 1: 1$, which indicate that these are Gd211 particles; the size of Gd211 particle in the single-domain GdBCO samples first decreases and then increases with increasing Gd211 particles in the PSPP. The Gd211 particle distribution and their mean size in the GdBCO samples were also calculated with the software Nano Measurer and are plotted in Figure 7. As we can see from Figure 7, the average size of the Gd211 particles decreases from 10.9 to $2.81 \mu \mathrm{m}$ with increasing sintering temperature from 25 to $1050^{\circ} \mathrm{C}$ corresponding to the samples $\mathrm{S} 1$ to $\mathrm{S} 4$. Here, $25^{\circ} \mathrm{C}$ corresponds to the unsintered samples. The average size of the Gd211 particles however increases from 2.81 to $3.96 \mu \mathrm{m}$ with the increasing sintering temperature from 1050 to $1200^{\circ} \mathrm{C}$, corresponding to the samples S4 to S7. The latter observation is in agreement with other experimental results in the literature that the larger the size of Gd211 particles in PSPP, the bigger the Gd211 particles in GdBCO samples [19, 20]. However, the results of the samples S1, S2, S3, and S4 indicate that the smaller the size of Gd211 particles in PSPP, the bigger Gd211 particles in GdBCO samples. These observed relationships allude to a new phenomenon which is substantially different from other results obtained in the traditional TSIG method. It can be conjectured that the smaller size Gd211 particles are of a lower chemical potential and thus easy to decompose, while the comparatively larger Gd211 particles grow bigger and bigger during the melting growth process of the single-domain GdBCO crystal.

Figures 3, 5, and 6 reveal that the largest levitation force is not obtained in samples with smaller Gd211 particles in PSPP (S1-S3); neither in samples with smaller Gd211 particles in single-domain GdBCO samples (S4-S5), rather in S6 with relatively larger Gd211 particles in the PSPP $(3.64 \mu \mathrm{m})$ and single-domain GdBCO bulk $(3.21 \mu \mathrm{m})$. This is closely related with the critical current densities $\left(J_{c}\right)$ of the samples because the levitation force can be expressed as a function of volume $v, J_{c}$, and the radius of the shielding current loop $r$ of the samples [21]. But $J_{c}$ is closely related with the flux pinning force of the samples, so the levitation force is directly dependent on the flux pinning properties of the sample.

In order to make clear this reason, we have to find out the relationship between the levitation force and the microstructure of the samples, especially the differences of Gd211 particles of the samples because the defects, such as stacking faults, dislocations, and twin boundaries around the Gd211/Gd123 interface can act as the flux pinning centers $[20,22,23]$. As we know that the fabricated samples are of the same initial composition $\left(\mathrm{Gd}_{2} \mathrm{O}_{3}+\mathrm{BaCuO}_{2}\right)$ and the same weight and shape, and the GdBCO bulks are also of nearly the same volume $v$ and the radius of the shielding current loop $r$, the levitation force is closely dependent on the Gd211 particles distribution and the density of the samples. For sample S1, the size of Gd211 particles is the largest (about $10.9 \mu \mathrm{m}$ ) in the single-domain GdBCO bulks. Furthermore, its high-level porosity is produced by the reaction of 011 with $\mathrm{Gd}_{2} \mathrm{O}_{3}$ phase. Consequently, the flux pinning force and levitation force $(25.1 \mathrm{~N})$ are at a minimum. 


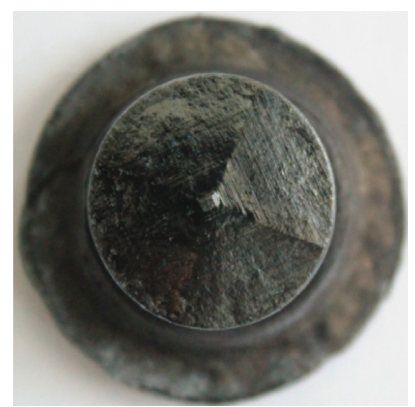

(a)

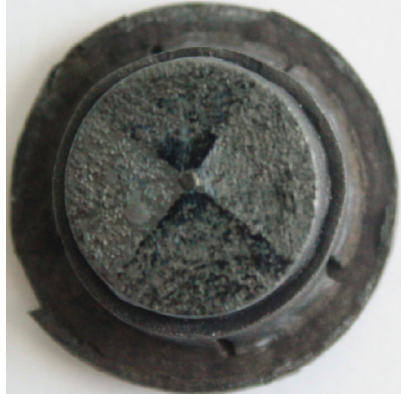

(b)



(c)

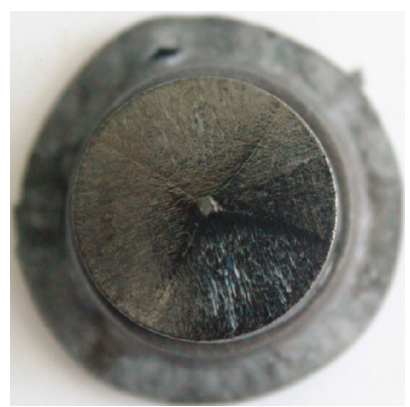

(d)

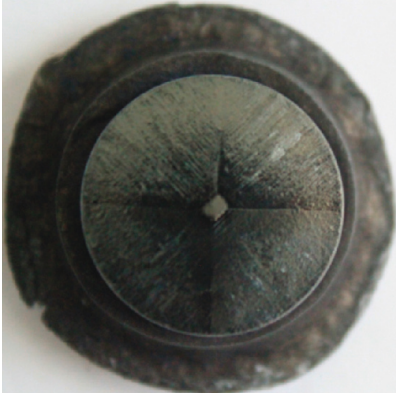

(e)

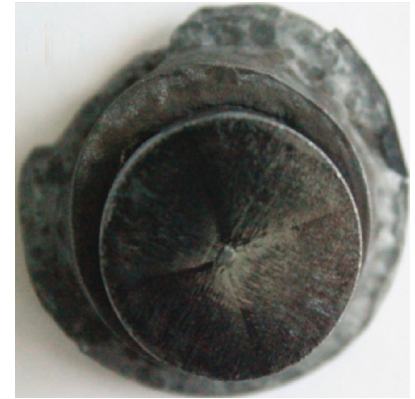

(f)

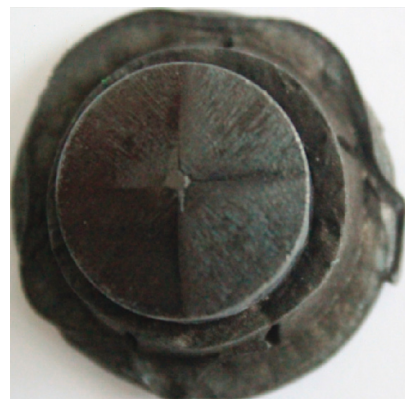

(g)

Figure 4: The morphology of the single-domain GdBCO samples prepared with the PSPP sintered at different temperatures. (a) S1 (25 $5^{\circ}$ ), (b) S2 $\left(950^{\circ} \mathrm{C}\right),(\mathrm{c}) \mathrm{S} 3\left(1000^{\circ} \mathrm{C}\right),(\mathrm{d}) \mathrm{S} 4\left(1050^{\circ} \mathrm{C}\right)$, (e) S5 $\left(1100^{\circ} \mathrm{C}\right),(\mathrm{f}) \mathrm{S} 6\left(1150^{\circ} \mathrm{C}\right)$, and $(\mathrm{g}) \mathrm{S} 7\left(1200^{\circ} \mathrm{C}\right)$.

Compared with $\mathrm{S} 1$, the porosity is gradually reduced in samples S2, S3, and S4, as shown in Figures 3(b), 3(c), and 3(d), respectively. Moreover, the number of larger size Gd211 particles is significantly reduced and the number of smaller size Gd211 particles is increased as it is evident in Figures 6(b), 6(c), and 6(d). The facts result in a gradual enhancement of the flux pinning and levitation force. The levitation force is increased from 25.1 to $29.1,31.5$, and $34.9 \mathrm{~N}$ corresponding the samples S1, S2, S3, and S4. For the samples S5 and S6, although the large size Gd211 particles in the PSPP (Figures 3(e) and 3(f)) result in an increment of the Gd211 particles, the porosity is significantly reduced, resulting in a further increase of levitation force to 36.7 and $38.1 \mathrm{~N}$. For the sample S7, the size of Gd211 particles is the largest in the PSPP (Figure 3); however, the Gd211 particles are smaller than those in the samples S1 and S2, while being slightly larger than those in the samples S5 and S6 (Figure 6). In addition, the porosity is reduced to a lowest level, but the difference is very insignificant compared with the sample S6, resulting in a reduction of the levitation force to $33.6 \mathrm{~N}$ (S7). The largest levitation force is achieved in the sample S6 with relatively larger size Gd211 particles and lower porosity.

\section{Conclusions}

Single-domain GdBCO bulks have been fabricated by the Gd + 011 TSIG technique in air using the PSPP with different Gd211 particle sizes and porosity. It is found that (i) the size of the Gd211 particles in the PSPP is increasing with increasing of the sintering temperature from 950 to $1200^{\circ} \mathrm{C}$, (ii) the porosity of the PSPP is decreasing with the increasing of the sintering temperature from 950 to $1200^{\circ} \mathrm{C}$, (iii) the largest levitation force is achieved in the sample S6 with

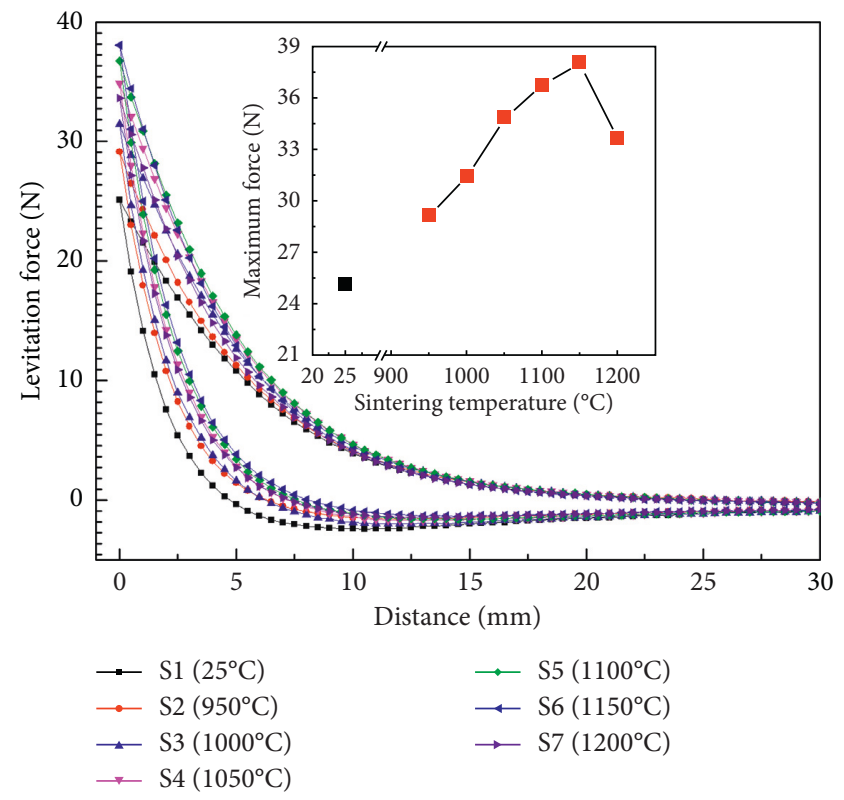

FIGURE 5: The levitation force of the GdBCO samples prepared with the PSPP sintered at different temperatures.

relatively larger size Gd211 particles and lower porosity, and (iv) in order to further improve the microstructure and physical properties of the single-domain GdBCO bulk, the PSPP should possess the following properties: (a) the Gd211 particles are of spherical or ellipsoidal shape and smaller size and (b) the Gd211 particles should improve the density and homogeneity and reduce the porosity of the PSPP. These 


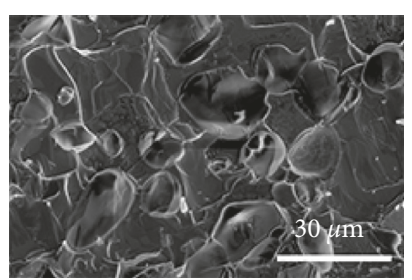

(a)

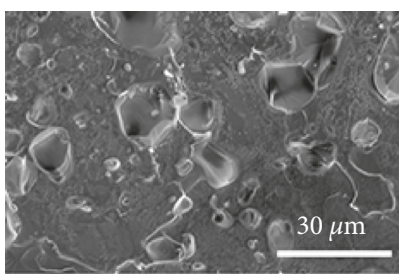

(b)

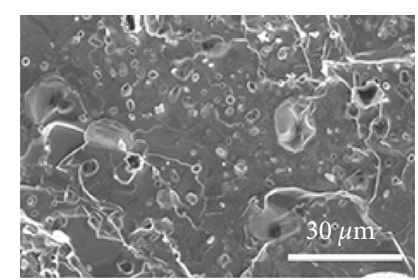

(c)

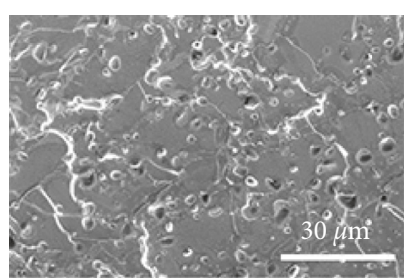

(d)



(e)

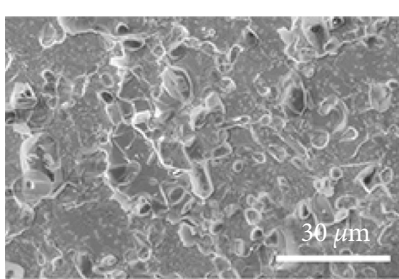

(f)



(g)

FIgURE 6: The SEM photographs of the GdBCO samples prepared with PSPP sintered at different temperatures. (a) $\mathrm{S} 1\left(25^{\circ} \mathrm{C}\right),(\mathrm{b}) \mathrm{S} 2\left(950^{\circ} \mathrm{C}\right)$, (c) S3 $\left(1000^{\circ} \mathrm{C}\right)$, (d) S4 $\left(1050^{\circ} \mathrm{C}\right)$, (e) S5 $\left(1100^{\circ} \mathrm{C}\right)$, (f) S6 $\left(1150^{\circ} \mathrm{C}\right)$, and (g) S7 $\left(1200^{\circ} \mathrm{C}\right)$.

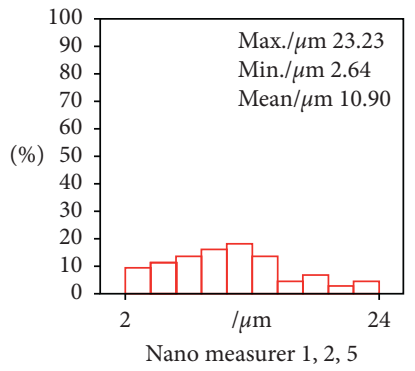

(a)

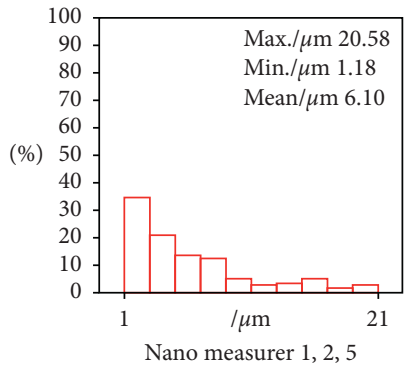

(b)

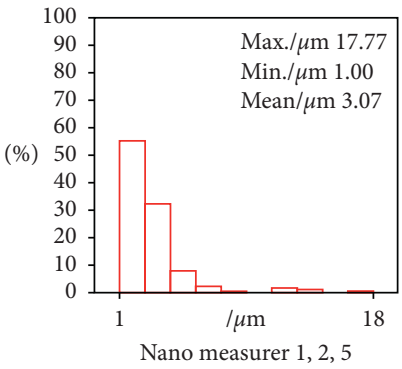

(c)

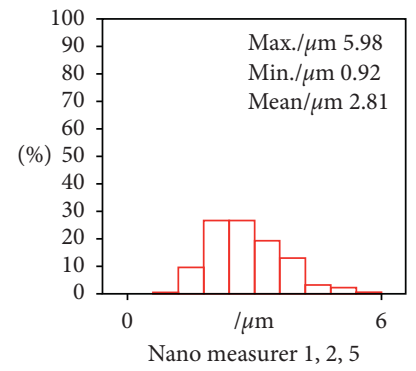

(d)

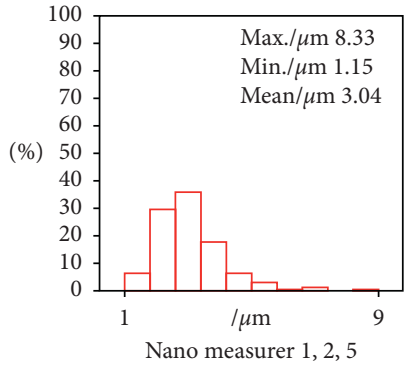

(e)

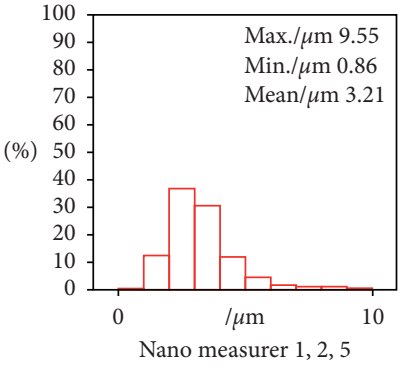

(f)

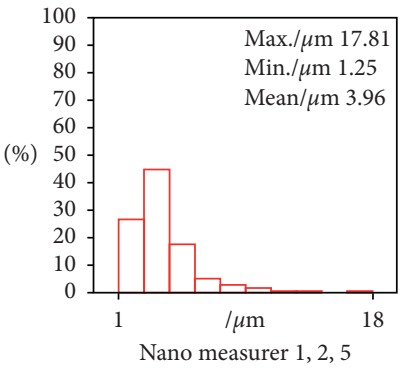

(g)

Figure 7: The Gd211 particle distribution of the GdBCO samples prepared with PSPP sintered at different temperatures. (a) $\mathrm{S} 1$ (25 $\left.{ }^{\circ} \mathrm{C}\right)$, (b) $\mathrm{S} 2$ $\left(950^{\circ} \mathrm{C}\right),\left(\right.$ c) S3 $\left(1000^{\circ} \mathrm{C}\right)$, (d) S4 $\left(1050^{\circ} \mathrm{C}\right)$, (e) S5 $\left(1100^{\circ} \mathrm{C}\right)$, (f) S6 $\left(1150^{\circ} \mathrm{C}\right)$, and $(\mathrm{g}) \mathrm{S} 7\left(1200^{\circ} \mathrm{C}\right)$.

results are very important in fabricating the high-quality single-domain GdBCO bulk superconductor.

\section{Data Availability}

The data used to support the findings of this study are available from the corresponding author upon request.

\section{Conflicts of Interest}

The authors declare that they have no conflicts of interest.

\section{Acknowledgments}

Helpful discussions with Professor Alireza Baghai-Wadji (University of Cape Town) are gratefully acknowledged. This work was supported by the National Natural Science Foundation in China (nos. 51572164 and 51342001), the Key Grant Project of Ministry of Education of the People's Republic of China (no. 311033), the Research Fund for the Doctoral Program of Higher Education of China (no. 20120202110003), the Innovation Team in Shaanxi Province (no. 2014KTC-18), and the Fundamental Research Funds for the Central Universities (no. GK201706001). 


\section{References}

[1] W. Gawalek, T. Habisreuther, M. Zeisberger et al., "Batchprocessed melt-textured YBCO with improved quality for motor and bearing applications," Superconductor Science and Technology, vol. 17, no. 10, pp. 1185-1188, 2004.

[2] F. N. Werfel, U. Floegel-Delor, R. Rothfeld, B. Goebel, D. Wip-pich, and T. Riedel, "Modelling and construction of a compact $500 \mathrm{~kg}$ HTS magnetic bearing," Superconductor Science and Technology, vol. 18, no. 2, pp. S19-S23, 2005.

[3] B. Oswald, K. J. Best, M. Setzer et al., "Reluctance motors with bulk HTS material," Superconductor Science and Technology, vol. 18, no. 2, pp. S24-S29, 2005.

[4] N. H. Badu, K. Iida, and D. A. Cardwell, "Enhanced magnetic flux pinning in nano-composite $\mathrm{Y}-\mathrm{Ba}-\mathrm{Cu}-\mathrm{O}$ superconductors," Physica C: Superconductivity and its Applications, vol. 445-448, no. 1, pp. 353-356, 2006.

[5] Y. F. Zhang, D. F. Zhou, T. Ida, M. Miki, and M. Izumi, "Meltgrowth bulk superconductors and application to an axial-gaptype rotating machine," Superconductor Science and Technology, vol. 29, no. 4, article 044005, 2016.

[6] S. Nariki, H. Teshima, and M. Morita, "Performance and applications of quench melt-growth bulk magnets," Superconductor Science and Technology, vol. 29, no. 3, article 034002, 2016

[7] E. S. Reddy and T. Rajasekharan, "Fabrication of textured $\mathrm{REBa}_{2} \mathrm{Cu}_{3} \mathrm{O}_{7} / \mathrm{RE}_{2} \mathrm{BaCuO}_{5}(\mathrm{RE}=\mathrm{Y}, \mathrm{Gd})$ composites by infiltration and growth of $\mathrm{RE}_{2} \mathrm{BaCuO}_{5}$ preforms by liquid phases," Superconductor Science and Technology, vol. 11, no. 5, pp. 523-534, 1998.

[8] G. Z. Li, D.-J. Li, J.-H. Deng, and W.-M. Yang, "Effects of liquid source mass and slow-cooling time on the infiltration growth of single-grain $\mathrm{Y}-\mathrm{Ba}-\mathrm{Cu}-\mathrm{O}$ bulk superconductors," Journal of Alloys and Compounds, vol. 551, no. 3, pp. 318-322, 2013.

[9] G. Z. Li, L. Dong, J.-H. Deng, X.-Y. Deng, and W.-M. Yang, “A coated infiltration growth technique for fabricating singlegrain $\mathrm{Y}-\mathrm{Ba}-\mathrm{Cu}-\mathrm{O}$ bulk superconductor," Journal of the American Ceramic Society, vol. 97, no. 12, pp. 3725-3728, 2014.

[10] D. Kenfaui, P. F. Sibeud, E. Louradour, X. Chaud, and J. G. Noudem, "An effective approach for the development of reliable YBCO bulk cryomagnets with high trapped Field performances," Advanced Functional Materials, vol. 24, no. 25, pp. 3996-4004, 2014.

[11] W. M. Yang, X. Zhi, S. L. Chen, M. Wang, J. Ma, and X. X. Chao, "Fabrication of single domain GdBCO bulk superconductors by a new modified TSIG technique," Physica C: Superconductivity and its Applications, vol. 496, no. 15, pp. 1-4, 2014.

[12] Y. X. Guo, W. M. Yang, J. W. Li, L. P. Guo, L. P. Chen, and Q. Li, "Effects of vertical temperature gradient on the growth morphology and properties of single domain YBCO bulks fabricated by a new modified TSIG technique," Crystal Growth and Design, vol. 15, no. 4, pp. 1771-1775, 2015.

[13] M. Wang, W. M. Yang, J. W. Li, Z. L. Feng, and P. T. Yang, "Comparison of the superconducting properties in GdBCO bulk superconductors fabricated with two different solid phases," Superconductor Science and Technology, vol. 28, no. 3, article 035004, 2015.

[14] Q. Li and W. M. Yang, "Preparation of high quality single domain SmBCO bulks by modified TSIG method in air with new solid phase of $\mathrm{Sm}_{2} \mathrm{O}_{3}+\mathrm{xBaCuO}_{2}$," Journal of Alloys and Compounds, vol. 650, no. 25, pp. 610-615, 2015.
[15] W. M. Yang, L. P. Chen, and X. J. Wang, "A new RE + 011 TSIG method for the fabrication of high quality and large size single domain YBCO bulk superconductors," Superconductor Science and Technology, vol. 29, no. 2, article 024004, 2016.

[16] S. L. Chen, W. M. Yang, J. W. Li, X. C. Yuan, J. Ma, and M. Wang, "A new 3D levitation force measuring device for REBCO bulk superconductors," Physica C: Superconductivity and its Applications, vol. 496, pp. 39-43, 2014.

[17] A. Mahmood, B. H. Jun, Y. H. Han, and C. J. Kim, "Effective pore control and current density in liquid infiltration growth processed Y-123 superconductors with Ag addition," Superconductor Science and Technology, vol. 23, no. 6, article 065005, 2010.

[18] A. Hu, N. Sakai, K. Ogasawara, and M. Murakami, "Microstructures and superconducting properties of single domain $\left(\mathrm{Sm}_{0.5}, \mathrm{Eu}_{0.5}\right) \mathrm{Ba}_{2} \mathrm{Cu}_{3} \mathrm{O}_{7-\delta}$ superconductors fabricated in air," Physica C: Superconductivity, vol. 366, no. 3, pp. 157-163, 2002.

[19] S. Nariki, S. J. Seo, N. Sakai, and M. Murakami, "Influence of the size of Gd211 starting powder on the critical current density of Gd-Ba-Cu-O bulk superconductor," Superconductor Science and Technology, vol. 13, no. 6, pp. 778-784, 2000.

[20] S. Nariki, N. Sakai, M. Murakami, and I. Hirabayashi, "High critical current density in $\mathrm{Y}-\mathrm{Ba}-\mathrm{Cu}-\mathrm{O}$ bulk superconductors with very fine Y211 particles," Superconductor Science and Technology, vol. 17, no. 2, pp. S30-S35, 2004.

[21] E. H. Brandt, "Rigid levitation and suspension of hightemperature superconductors by magnets," American Journal of Physics, vol. 58, no. 1, pp. 43-49, 1990.

[22] D. Lee, X. Chaud, and K. Salama, "Effects of silver and $\mathrm{Y}_{2} \mathrm{BaCuO}_{5}$ inclusions on the transport current density and its anisotropy of oriented-grained $\mathrm{YBa}_{2} \mathrm{Cu}_{3} \mathrm{Ox}$ /silver composites," Japanese Journal of Applied Physics, vol. 31, no. 8, pp. 2411-2419, 1992.

[23] K. Salama and D. F. Lee, "Progress in melt texturing of $\mathrm{YBa}_{2} \mathrm{Cu}_{3} \mathrm{Ox}$ superconductor," Superconductor Science and Technology, vol. 7, no. 4, pp. 177-193, 1994. 




The Scientific World Journal
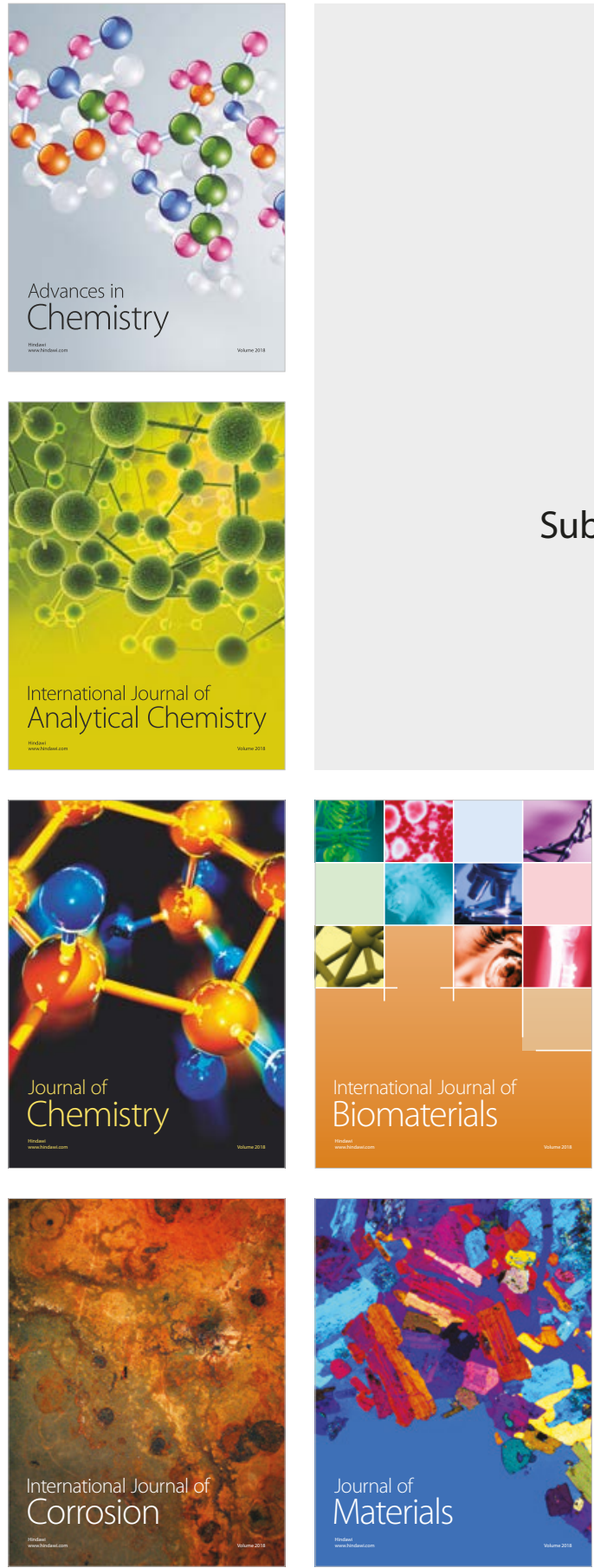

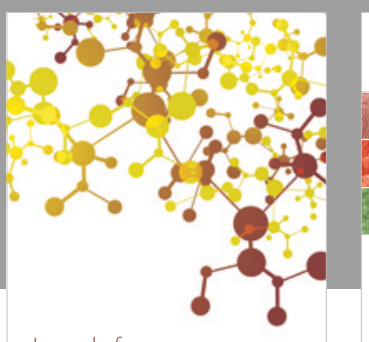

Journal of

Applied Chemistry
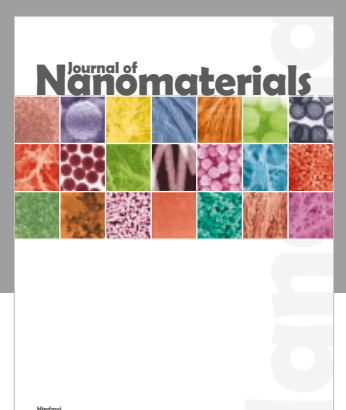

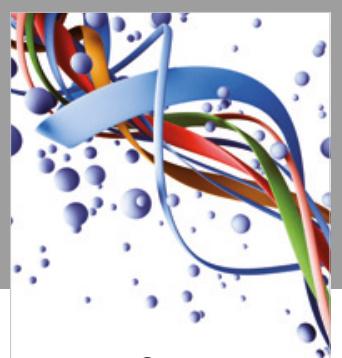

Scientifica

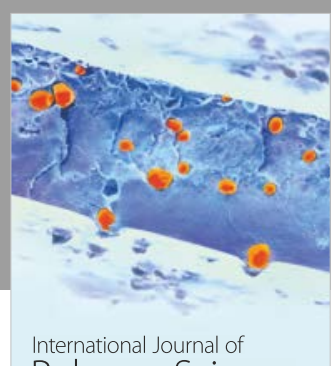

Polymer Science

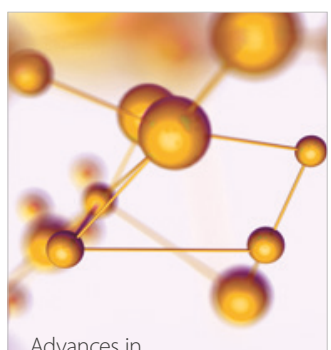

Physical Chemistry
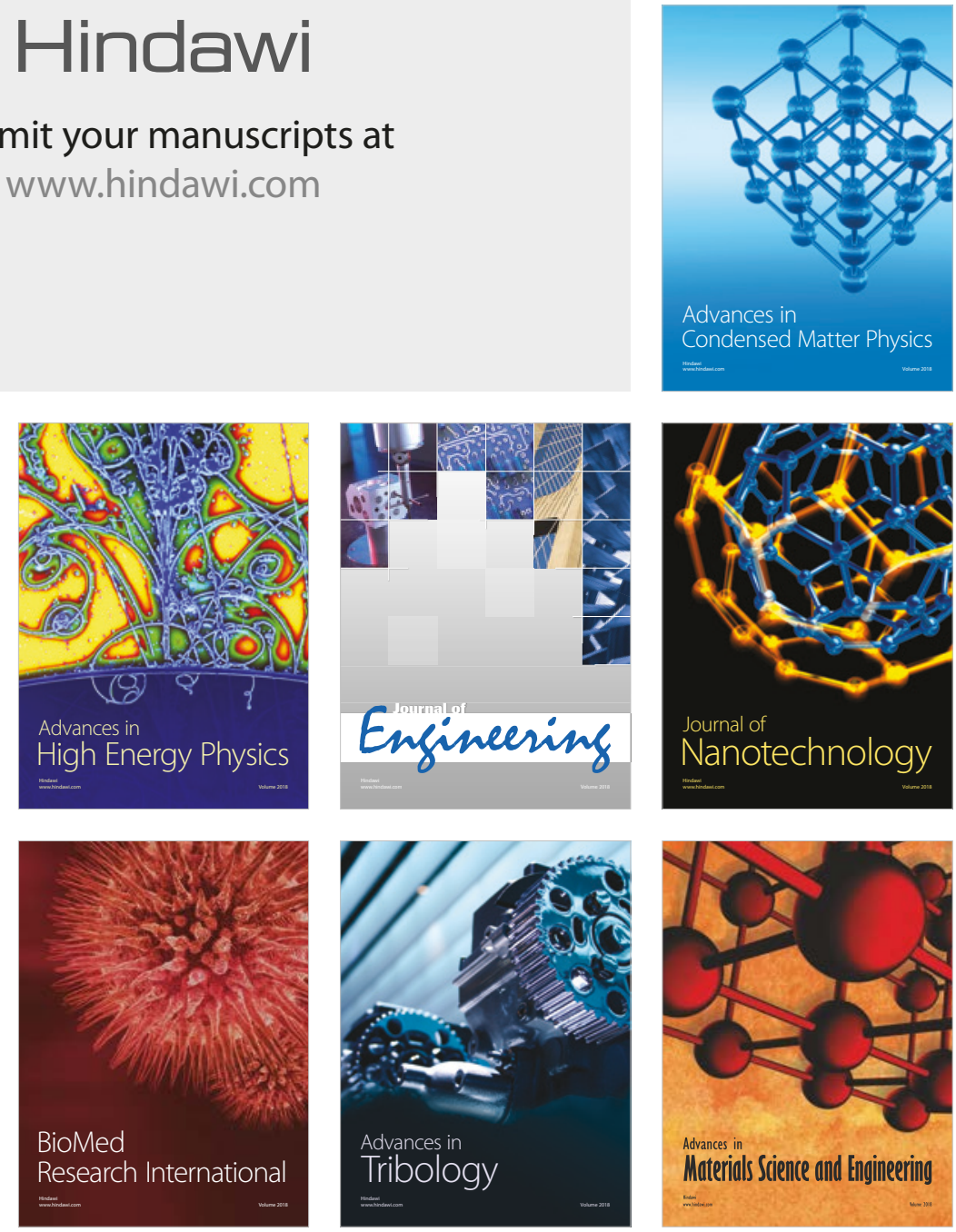